Article

\title{
Evaluation of Precipitation Estimates CMORPH-CRT on Regions of Mexico with Different Climates
}

\author{
José L. Bruster-Flores ${ }^{1}$, Ruperto Ortiz-Gómez ${ }^{2, *}$ (D), Adrian L. Ferriño-Fierro ${ }^{1}$, \\ Víctor H. Guerra-Cobián ${ }^{1}$, Dagoberto Burgos-Flores ${ }^{3}(\mathbb{D}$ and Liliana G. Lizárraga-Mendiola 4 (D) \\ 1 Facultad de Ingeniería Civil, Universidad Autónoma de Nuevo León, Av. Universidad s/n, Ciudad \\ Universitaria, San Nicolás de los Garza 66455, Mexico \\ 2 Unidad Académica de Ingeniería, Universidad Autónoma de Zacatecas, Av. Ramón López Velarde, 801, \\ Zacatecas 98000, Mexico \\ 3 Departamento de Ingeniería Civil y Minas, Universidad de Sonora, Blvd. Luis Encinas y Calle Rosales, \\ Hermosillo 83000, Mexico \\ 4 Cuerpo Académico de Ingeniería Civil Sustentable y Tecnología de Materiales, Universidad Autónoma del \\ Estado de Hidalgo, Carr. Pachuca-Tulancingo km 4.5 Col. Carboneras, Mineral de la Reforma 42184, Mexico \\ * Correspondence: ortizgr@uaz.edu.mx; Tel.: +52-492-925-6690
}

Received: 2 July 2019; Accepted: 13 August 2019; Published: 19 August 2019

\begin{abstract}
Satellite-based precipitation (SBP) products with global coverage have the potential to overcome the lack of information in places where there are no rain gauges to perform hydrological analyses; however, it is necessary to evaluate the reliability of the SBP products. In this study, we evaluated the performance of the Climate Prediction Center morphing technique with corrected bias (CMORPH-CRT) product in 14 sites in Mexico. The evaluation was carried out using two approaches: (1) using categorical metrics that include indicators of probability of detection (POD), false alarm rate (FAR), critical success index (CSI), and frequency bias index (FBI); and (2) through statistical indicators such as the mean absolute error (MAE), root mean square error (RMSE), relative bias (RB), and correlation coefficient (CC). The analysis was carried out with two levels of temporal aggregation: $30 \mathrm{~min}$ and daily. The results indicate that the CMORPH-CRT product overestimates the number of precipitation events in most cases since FBI values greater than 1 in $78.6 \%$ of analyzed stations were obtained. Also, we obtained CC values in the range of 0.018 to 0.625 , which implied weak to moderate correlations, and found that in all stations, the CMORPH-CRT product overestimates the precipitation $(\mathrm{RB}>0)$.
\end{abstract}

Keywords: satellite-based precipitation products; $\mathrm{CMORPH}$; Mexico; categorical metrics; accuracy evaluation

\section{Introduction}

With the advancement of technology, it has been possible to develop more complex hydrological models to better describe the interaction of the hydrological cycle with a basin system, to improve both the management of water resources and the hydraulic infrastructure of the populations settled in the basin. Such models require more detailed information on the hydrological cycle components, either as input data for the hydrological calculation processes or as data for the calibration and validation processes. Precipitation data are one of the main input variables of hydrological models that can be obtained by terrestrial measurements or remote sensor estimates, with the first acquisition method being the most accurate [1]. Recently, satellite precipitation estimates with global coverage and high spatial and temporal resolution have become available, which can compensate for the lack of information in places where there are no rain gauges. The algorithms for estimating precipitation from satellite measurements include: the Precipitation Estimation from Remote Sensing Information using 
Artificial Neural Network (PERSIANN) [2], Climate Precipitation Center (CPC) Morphing Technique (CMORPH) [3], and Tropical Rainfall Measuring Mission (TRMM) Multi-Satellite Precipitation Analysis (TMPA) [4]. However, despite the advantages of uninterrupted global coverage and high resolution, the question arises as to how reliable it is to use satellite precipitation estimates. In other words, the question is whether the algorithms that produce the estimates can accurately determine precipitation [5]. To answer such questions, several studies have been conducted around the world to evaluate satellite precipitation estimates. To cite some examples, Jiang et al. evaluated the satellite-based precipitation (SBP) products TRMM 3B42V7 and CMORPH in 11 sites distributed in different districts of Shanghai for the period from January 2010 to December 2011 [6]. Kumar et al. evaluated the SBP products TRMM 3B42V7 and CMORPH for the period from June to August 2005-2010 in 6 sites located within the Gandak River basin, which is a transboundary basin between India, China, and Nepal [7]. Haile et al. evaluated the SBP product CMORPH in 8 sites located in the Gilgel Abbay basin in Ethiopia for the period from June to August 2007 [8]. Nastos et al. evaluated the SBP product TRMM 3B42V7 on Greece for the 1998-2008 period, in relation to a gridded precipitation database constructed from interpolating data from 96 rain gauges using the Kriging method. They found that the TRMM 3B42V7 product underestimates precipitation over high altitude areas and overestimates it over the plains and coastal regions [9]. Wang and Wolff evaluated the SBP product TRMM 3G68V6 using the radar product 2A53, and the digital swing gauge 2A56 product for the period 1998-2009 at the Melbourne site in Florida, and they found that the TRMM 3G68V6 product is in good overall agreement with 2A53 radar product at lower rain rates, but the agreement becomes poorer at higher rain rates [10]. Quirino et al. evaluated the SBP products TRMM 3B42V7 and 3B42RT in the period from January 1998 to October 2015 , with respect to the rainfall data of the meteorological station of the municipality of Santo Antonio de Goiás, Brazil; they observed that the product 3B42V7 overestimates precipitation during the rainy season and underestimates it in the dry period [11]. Avila-Carrasco et al. evaluated the SBP product TRMM 3B43V7 on the Santiago River basin in Mexico for the 1998-2010 period, in relation to a gridded precipitation database constructed from interpolating the data from 85 rain gauges using the Kriging method. They found that the TRMM 3B43V7 product tends to underestimate precipitation in the coastal and mountainous regions that correspond to the wettest regions of the study and tends to overestimate rainfall on the plateau which is the driest region of the study [12]. In previous works, the potential of SBP products to provide information to regions where there are no ground-based observations of precipitation is indicated. In Mexico, there are regions with these conditions, so it is necessary to evaluate if the SBP products are a viable alternative to overcome the lack of available information. The objective of this research is to evaluate the SBP CMORPH-CRT product in 14 sites in Mexico with different climates, in regards to the precipitation information recorded in 14 weather stations, one per site. The evaluation was carried out for two levels of temporary aggregation: $30 \mathrm{~min}$ and daily.

\section{Materials and Methods}

The study sites were established based on the location of the weather stations. 14 stations were selected based on the length of their records and their spatial distribution in relation to the type of climate (Figure 1). 


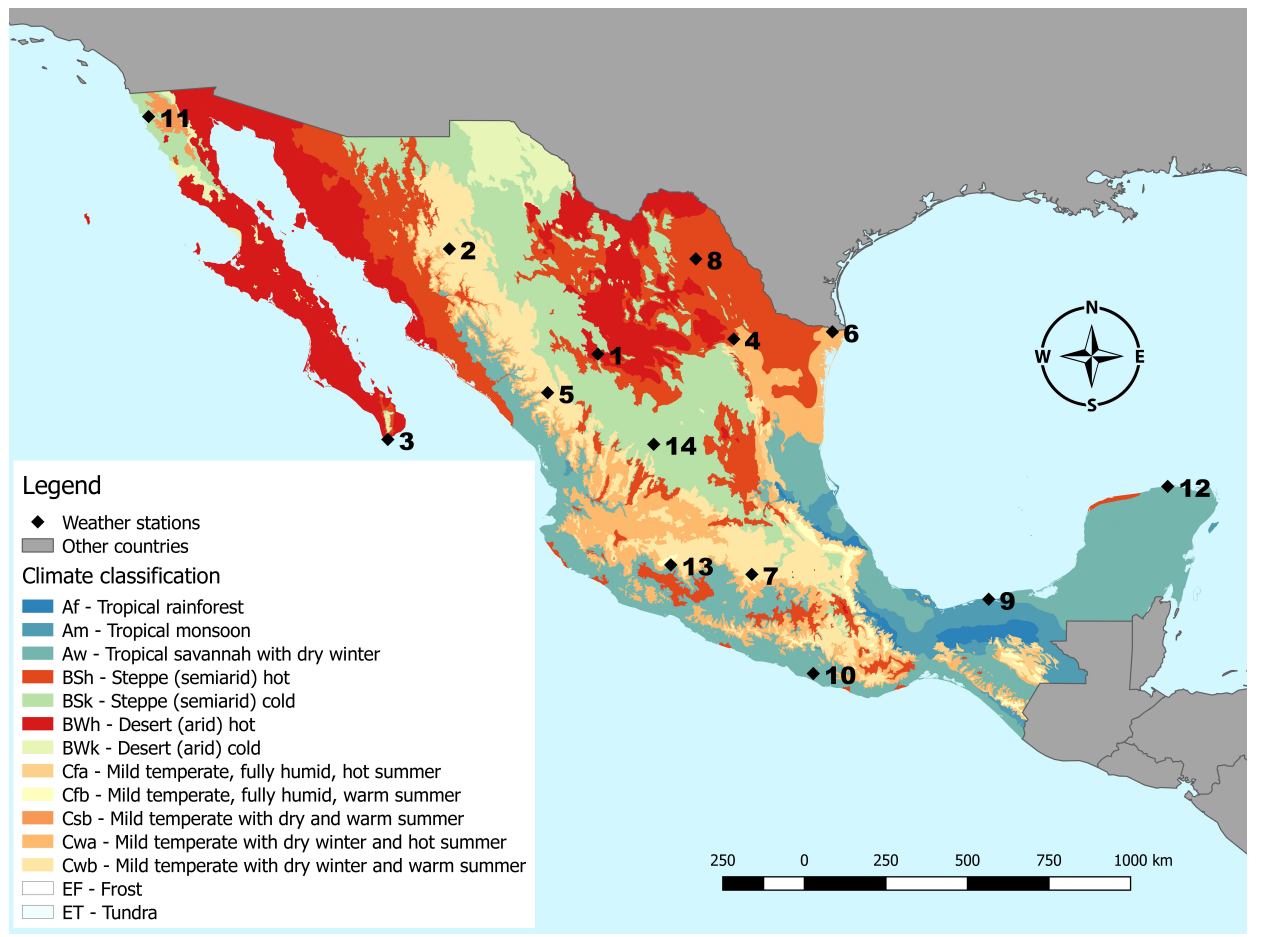

Figure 1. Study sites and types of climate in Mexico.

\subsection{Precipitation Data Set}

\subsubsection{Precipitation Data of the Weather Stations}

The selected stations for this research are administered by the General Coordination of the National Meteorological Service (CGSMN, by its initials in Spanish) that belongs to the National Water Commission (CONAGUA, by its initials in Spanish), except for the "Fierro, N.L. SAHM" station, which is part of the Hydrometeorological Alert Systems at Basin level (SAHs) developed and implemented by the National Center for Disaster Prevention (CENAPRED, by its initials in Spanish) and is administered by Civil Protection of the State of Nuevo Leon. The weather stations analyzed (Table 1) are automatic stations. The precipitation records correspond to the accumulated precipitation in a 10-min interval and the reference time of the data is UTC.

Table 1. Detailed information of the weather stations.

\begin{tabular}{|c|c|c|c|c|c|c|c|c|}
\hline $\begin{array}{l}\text { Station } \\
\text { ID }\end{array}$ & Station Name & State & Municipality & Latitude & Longitude & $\begin{array}{l}\text { Altitude } \\
\text { Masl }\end{array}$ & $\begin{array}{l}\text { Analysis } \\
\text { Period }\end{array}$ & $\begin{array}{l}\text { Climate } \\
\text { Code }\end{array}$ \\
\hline 1 & Agustín Melgar & Durango & Nazas & 25.2633 & -104.0661 & 1226 & $2003-2018$ & BWh \\
\hline 2 & Basaseachi & Chihuahua & Ocampo & 28.1992 & -108.2089 & 1973 & 2000-2018 & Cwb \\
\hline 3 & Cabo San Lucas & Baja California Sur & Los Cabos & 22.8811 & -109.9264 & 224 & 2000-2018 & BWh \\
\hline 4 & Fierro, N.L. SAHM & Nuevo León & Monterrey & 25.6828 & -100.2719 & 500 & $2001-2017$ & BSh \\
\hline 5 & Las Vegas & Durango & San Dimas & 24.1858 & -105.4661 & 2398 & 2003-2018 & Cwb \\
\hline 6 & Matamoros & Tamaulipas & Matamoros & 25.8858 & -97.5186 & 4 & $2000-2018$ & Cwa \\
\hline 7 & Nevado de Toluca & México & Toluca & 19.1167 & -99.7667 & 4139 & 2000-2018 & ET \\
\hline 8 & Nueva Rosita & Coahuila & $\begin{array}{l}\text { San Juan de } \\
\text { Sabinas }\end{array}$ & 27.9200 & -101.3300 & 366 & 2003-2018 & BSh \\
\hline 9 & Paraíso & Tabasco & $\begin{array}{l}\text { Paraíso } \\
\text { Santiago }\end{array}$ & 18.4233 & -93.1556 & 4 & 2003-2018 & Am \\
\hline 10 & Pinotepa Nacional & Oaxaca & $\begin{array}{l}\text { Pinotepa } \\
\text { Nacional }\end{array}$ & 16.3497 & -98.0525 & 195 & 2002-2018 & $\mathrm{Aw}$ \\
\hline 11 & $\begin{array}{l}\text { Presa Emilio López } \\
\text { Zamora (Ensenada) }\end{array}$ & Baja California & Ensenada & 31.8914 & -116.6033 & 32 & 2000-2018 & BSk \\
\hline 12 & Río Lagartos & Yucatán & Río Lagartos & 21.5711 & -88.1603 & 5 & 2000-2018 & Aw \\
\hline 13 & Uruapan & Michoacán & Uruapan & 19.3810 & -102.0291 & 1606 & 1999-2017 & Cwa \\
\hline 14 & Zacatecas & Zacatecas & Guadalupe & 22.7467 & -102.5061 & 2270 & 2000-2018 & BSk \\
\hline
\end{tabular}




\subsubsection{SBP CMORPH-CRT Product}

SBP CMORPH-CRT product is generated by the CPC of the National Office of Oceanic and Atmospheric Administration (NOAA). A detailed description of the CMORPH algorithm can be found in Joyce et al. [3]. We used version 1.0 of the SBP CMORPH, which is generated using a fixed algorithm and inputs of fixed versions to ensure best possible homogeneity, covering the entire TRMM/GPM era since January 1998 to date and includes the raw, satellite only precipitation estimates as well as bias corrected and gauge-satellite blended precipitation products [13]. Of the three types of products included in version 1.0, estimates with bias correction were used. The files containing the precipitation estimates used are available on the FTP site of the CPC through the following link: http://ftp.cpc.ncep.noaa.gov/precip/CMORPH_V1.0/CRT/8km-30min/. For a detailed description of the files, see Appendix A. The GNU Octave software was used to read the binary files and extract the information of the precipitation estimates from the cells matching the location of each station.

\subsection{Evaluation Methods}

The evaluation of the CMORPH precipitation was carried out through two approaches: (1) analysis of the capacity to detect precipitation; and (2) quantification of the accuracy or discrepancy between the CMORPH estimates and the precipitation data of the rain gauges of the weather stations $[6,7,14]$. For the first approach, precipitation data were considered categorical events and four indicators were used: probability of detection (POD), false alarm rate (FAR), critical success rate (CSI), and frequency bias index (FBI). To carry out the calculation of such indicators, a contingency table was used as a tool, since it allows a summary view of the frequency in which a precipitation event is detected or not by the rain gauge or the CMORPH algorithm. There are 4 possible combinations that are shown in Table 2 and that were defined as follows: (1) hit, both the rain gauge and the CMORPH algorithm detect the precipitation event; (2) miss, the rain gauge detects the precipitation event, but the CMORPH algorithm does not; (3) false alarm, the algorithm CMORPH detects the event of precipitation, but the rain gauge does not; and (4) correct negative, neither the rain gauge nor the CMORPH algorithm detect the precipitation event.

Table 2. Table of contingencies for the analysis of precipitation detection capacity.

\begin{tabular}{cccc}
\hline \multicolumn{4}{c}{ CMORPH Algorithm } \\
\hline & Precipitation Detected & Yes & No \\
\hline \multirow{2}{*}{ Rain Gauge } & Yes & Hit (a) & Miss (c) \\
& No & False alarm (b) & Correct negative (d) \\
\hline
\end{tabular}

The probability of detection (POD) is the fraction of precipitation events detected by the CMORPH algorithm. This indicator is sensitive to hits but ignores false alarms, so it must be used in conjunction with the false alarm rate (FAR). The false alarm rate (FAR) is the fraction that did not occur from the events detected by the CMORPH algorithm, which is sensitive to false alarms, but ignores misses. The critical success index (CSI) is the fraction of all detected events (CMORPH algorithm or rain gauge) that was correctly detected by the CMORPH algorithm, it does not consider the correct negatives. The frequency bias index (FBI) is the relationship between the events detected by the CMORPH algorithm and those detected by the rain gauge. This indicator allows us to know if the number of precipitation events detected by the SBP product is equal to that observed by the rain gauge or if the SBP product overestimates or underestimates the number of precipitation events, it must be used in conjunction with the other three indicators. Table 3 presents the indicators, their range, and optimal value, as well as the equations used for their calculation; $a$ is the total of hits, $b$ is the total of false alarms, and $c$ is the total of misses. 
Table 3. Indicators for the analysis of precipitation detection capacity.

\begin{tabular}{ccccc}
\hline Indicator & Range & Optimal Value & \multicolumn{2}{c}{ Equation } \\
\hline Probability of detection (POD) & {$[0,1]$} & 1 & POD $=\frac{a}{a+c}$ & $(1)$ \\
False alarm rate (FAR) & {$[0,1]$} & 0 & FAR $=\frac{b}{a+b}$ & $(2)$ \\
Critical success index (CSI) & {$[0,1]$} & 1 & CSI $=\frac{a}{a+b+c}$ & $(3)$ \\
Frequency bias index (FBI) & {$[0, \infty]$} & 1 & FBI $=\frac{a+b}{a+c}$ & $(4)$ \\
\hline
\end{tabular}

In the second evaluation approach, precipitation data was considered a continuous variable and four indicators were used to measure the accuracy or discrepancy between the precipitation data observed by the station and the CMORPH estimates: mean absolute error (MAE), root of the mean square error (RMSE), relative bias (RB) and correlation coefficient (CC). Both the MAE and the RMSE, measure the accuracy of the estimate regarding the observed data. The RMSE penalizes errors of greater magnitude, making it more sensitive to these errors than the MAE is [15]. The RB allows knowing if the CMORPH algorithm underestimates or overestimates precipitation. The CC measures the linear association between the rain gauge records and the CMORPH estimates. Table 4 shows the equations used to calculate these indicators, where $n$ represents the total number of pairs of data analyzed, $E_{i}$ is the precipitation estimated by the CMORPH algorithm, $O_{i}$ is the precipitation observed by the station, $\bar{E}$ and $\bar{O}$ are the mean values of the precipitation data estimated by the CMORPH algorithm and those observed by the station, respectively.

Table 4. Indicators for the quantification of the precision or discrepancy between the CMORPH estimates and the precipitation data of the rain gauges.

\begin{tabular}{|c|c|c|c|c|}
\hline Indicator & Range & Optimal Value & Equation & \\
\hline Mean absolute error (MAE) & {$[0, \infty]$} & 0 & MAE $=\frac{1}{n} \cdot \sum_{i=1}^{n}\left|E_{i}-O_{i}\right|$ & (5) \\
\hline Root of the mean square error (RMSE) & {$[0, \infty]$} & 0 & RMSE $=\sqrt{\frac{1}{n} \cdot \sum_{i=1}^{n}\left(E_{i}-O_{i}\right)^{2}}$ & (6) \\
\hline Relative bias (RB) & {$[-\infty, \infty]$} & 0 & $\begin{array}{c}\mathrm{RB}=\frac{\sum_{i=1}^{n}\left(E_{i}-O_{i}\right)}{\sum_{i=1}^{n} O_{i}} \\
\sum_{i=1}^{n}\left(E_{i}-\bar{E}\right) \cdot\left(O_{i}-\bar{O}\right)\end{array}$ & (7) \\
\hline Correlation coefficient (CC) & {$[-1,1]$} & 1 & $\mathcal{C}=\frac{\sqrt{\sum_{i=1}^{n}\left(E_{i}-\bar{E}\right)^{2}} \cdot \sqrt{\sum_{i=1}^{n}\left(O_{i}-\bar{O}\right)^{2}}}{2}$ & (8) \\
\hline
\end{tabular}

The evaluation was carried out for two levels of aggregation of precipitation data: $30 \mathrm{~min}$ and daily. The observations of the stations were accumulated at $30 \mathrm{~min}$ and $24 \mathrm{~h}$. The CMORPH estimates were accumulated only at $24 \mathrm{~h}$ since the temporal resolution of the CMORPH data is $30 \mathrm{~min}$.

\section{Results}

\subsection{Analysis of Precipitation Detection Capacity}

The determination of the total of hits, false alarms and misses in the detection of precipitation was carried out establishing three threshold values for each of the two levels of temporal aggregation analyzed (30 min and daily). In the first threshold, any record greater than zero was considered as precipitation detected, in the second, it was considered to be detected if the record was equal to or greater than $0.1 \mathrm{~mm}$, and the third, if it was equal to or greater than $0.25 \mathrm{~mm}$. The threshold values used in the analysis of the precipitation detection capacity were selected to consider: (1) any record greater than zero, and (2) any record detected as a function of the resolution of the rain gauges $(0.1 \mathrm{~mm}$ and $0.25 \mathrm{~mm}$ ) [8]. The following trends were observed for both levels of temporal aggregation, with respect to the increase of the threshold value: in most of the study sites POD, FAR and FBI decreased, while CSI increased (Figures 2-5).

Tables 5 and 6 concentrate the results of the analysis of precipitation detection capacity. The maximum values are highlighted with a blue border, the minimum values with a red border, and for the FBI indicator, the values close to 1 are highlighted with a green border around the number. For the accumulated precipitation records in $30 \mathrm{~min}$, poor performance in the detection capacity is observed, 
since the maximum POD values obtained in station 2 reach hardly 0.5 , this implies that for this temporal aggregation level the CMORPH-CRT algorithm detects less than $50 \%$ of precipitation events at study sites. Together with the low POD values, high FAR values are observed, which implies that, for the study sites, the CMORPH-CRT algorithm detects a high number of precipitation events that did not occur. The combination of low POD values and high FAR values explains the low values obtained for the CSI indicator. Regarding the FBI indicator, the CMORPH-CTR algorithm overestimates the number of precipitation events in most study sites and three sites showed values close to 1.

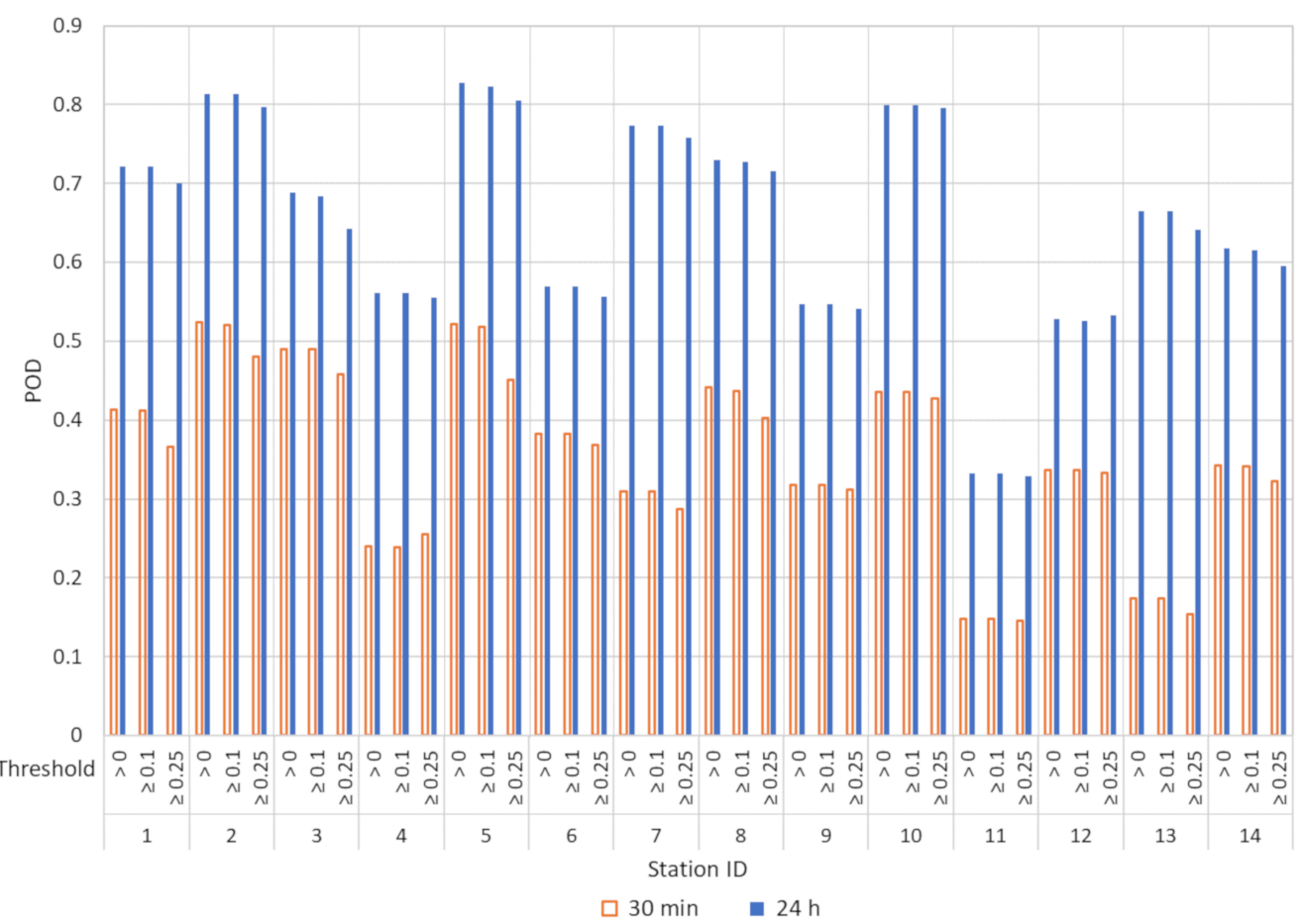

Figure 2. Probability of detection (POD) results by station for different analyzed thresholds.

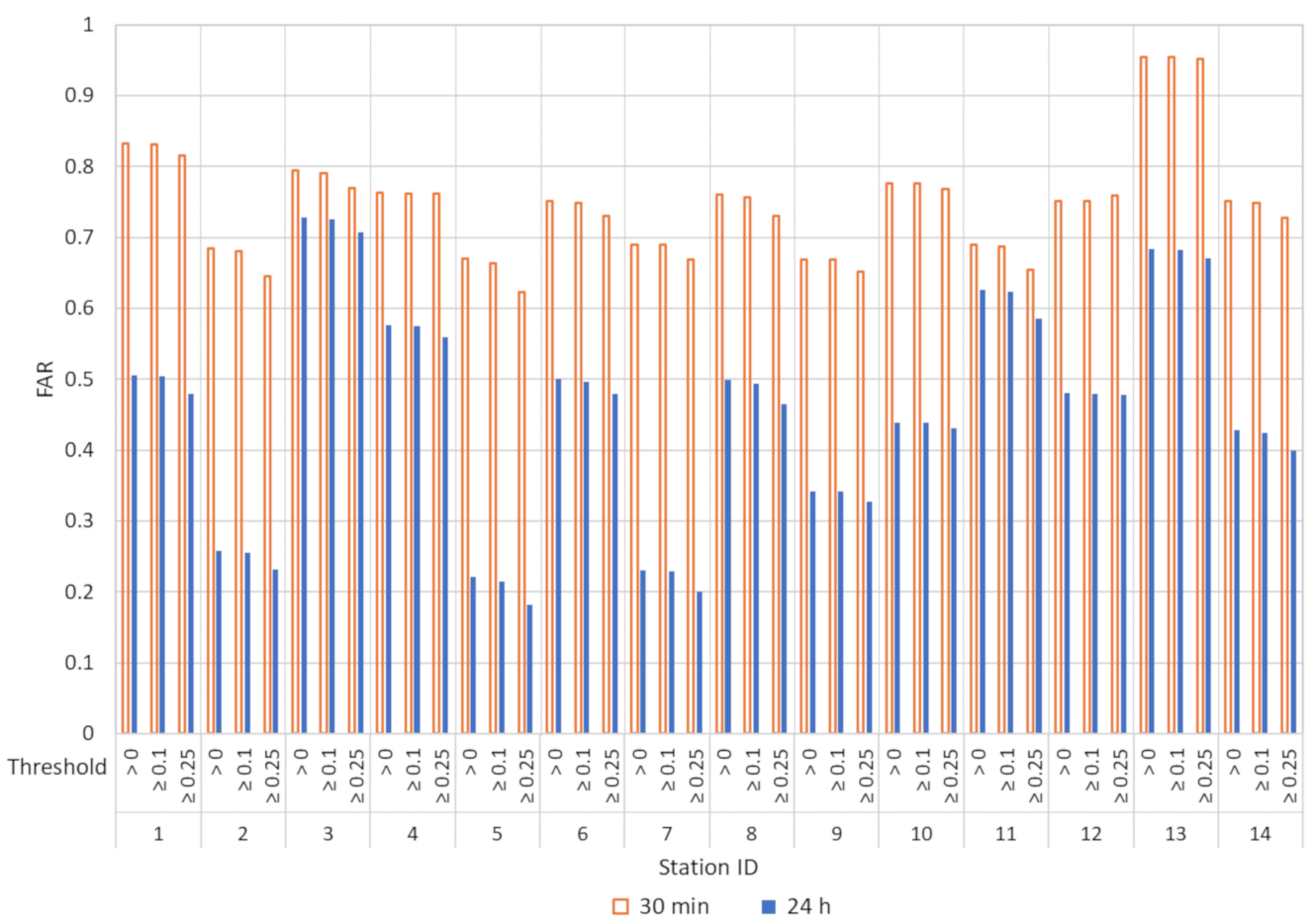

Figure 3. False alarm rate (FAR) results by station for different analyzed thresholds. 


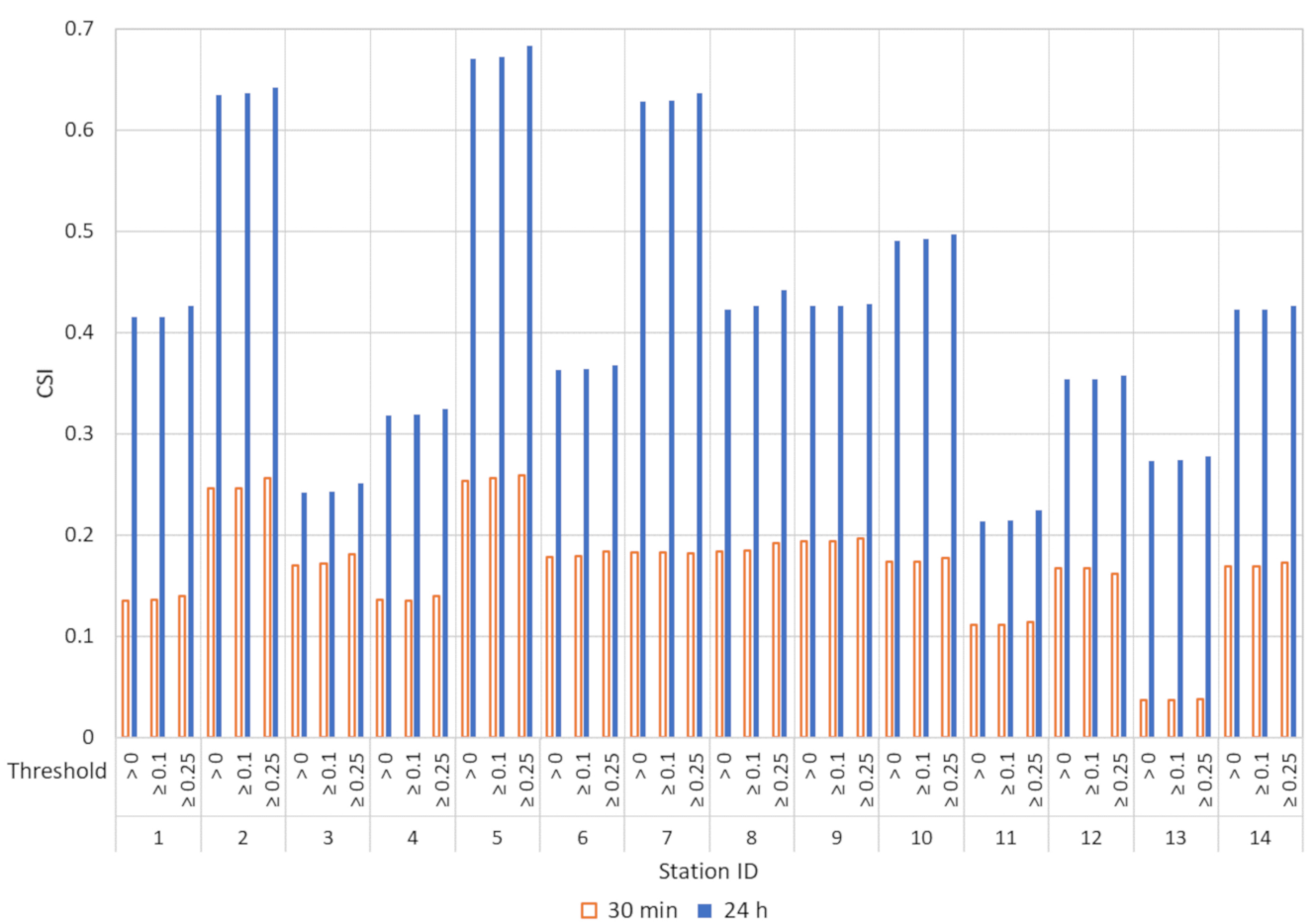

Figure 4. Critical success index (CSI) results by station for different analyzed thresholds.

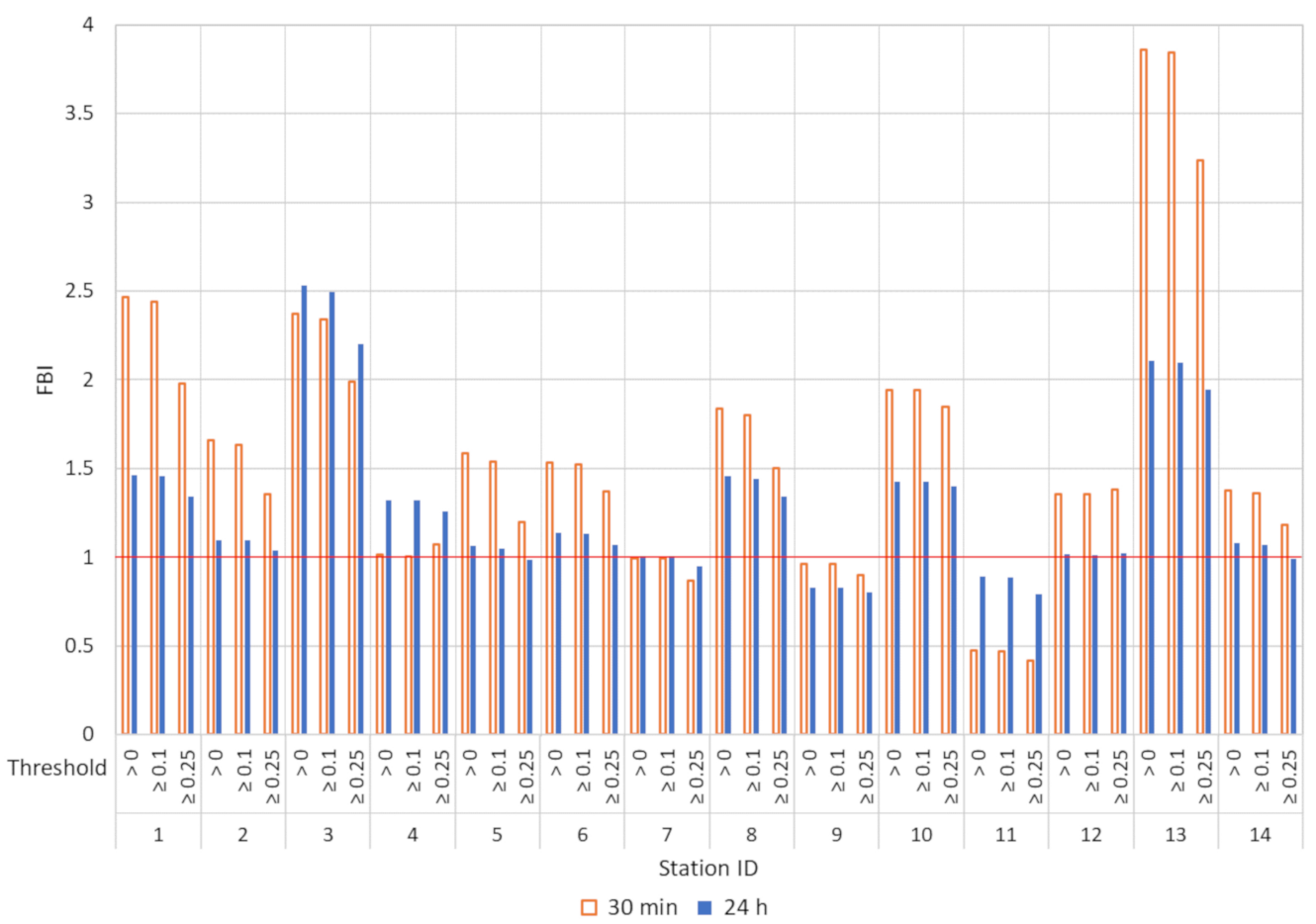

Figure 5. Frequency bias index (FBI) results by station for different analyzed thresholds.

Regarding the accumulated precipitation records in $24 \mathrm{~h}$, the CMORPH-CRT algorithm has a better performance in the precipitation detection capacity. In most of the study sites, POD values greater than 0.5 were obtained, only at the station 11 site a POD value less than 0.5 was obtained. The FAR indicator values improved in all cases, values below 0.5 were obtained in most of the study sites. The improvements in the POD and the FAR are reflected in the CSI indicator, which shows values greater than 0.4 in most of the study sites. The FBI indicator also improved, increasing the 
number of sites with a value close to 1 ; however, it remains the tendency to overestimate the number of precipitation events.

Table 5. Results of the precipitation detection capacity analysis (POD and FAR).

\begin{tabular}{|c|c|c|c|c|c|c|c|c|c|c|c|c|}
\hline \multirow{6}{*}{ Station ID } & \multicolumn{12}{|c|}{ Indicator } \\
\hline & \multicolumn{6}{|c|}{ POD } & \multicolumn{6}{|c|}{ FAR } \\
\hline & \multicolumn{6}{|c|}{ Temporal Aggregation Level } & \multicolumn{6}{|c|}{ Temporal Aggregation Level } \\
\hline & $\begin{array}{c}30 \\
(\mathrm{~min})\end{array}$ & $\begin{array}{c}30 \\
(\mathrm{~min})\end{array}$ & $\begin{array}{c}30 \\
(\mathrm{~min})\end{array}$ & $\begin{array}{l}24 \\
\text { (h) }\end{array}$ & $\begin{array}{l}24 \\
\text { (h) }\end{array}$ & $\begin{array}{l}24 \\
\text { (h) }\end{array}$ & $\begin{array}{c}30 \\
(\mathrm{~min})\end{array}$ & $\begin{array}{c}30 \\
\text { (min) }\end{array}$ & $\begin{array}{c}30 \\
(\mathrm{~min})\end{array}$ & $\begin{array}{l}24 \\
\text { (h) }\end{array}$ & $\begin{array}{l}24 \\
\text { (h) }\end{array}$ & $\begin{array}{l}24 \\
\text { (h) }\end{array}$ \\
\hline & \multicolumn{3}{|c|}{ Threshold } & \multicolumn{3}{|c|}{ Threshold } & \multicolumn{3}{|c|}{ Threshold } & \multicolumn{3}{|c|}{ Threshold } \\
\hline & $>0$ & $\geq 0.1$ & $\geq 0.25$ & $>0$ & $\geq 0.1$ & $\geq 0.25$ & $>0$ & $\geq 0.1$ & $\geq 0.25$ & $>0$ & $\geq 0.1$ & $\geq 0.25$ \\
\hline 1 & 0.413 & 0.412 & 0.366 & 0.722 & 0.722 & 0.700 & 0.832 & 0.831 & 0.815 & 0.506 & 0.505 & 0.479 \\
\hline 2 & 0.524 & 0.520 & 0.480 & 0.814 & 0.814 & 0.797 & 0.684 & 0.681 & 0.645 & 0.258 & 0.256 & 0.232 \\
\hline 3 & 0.490 & 0.490 & 0.458 & 0.689 & 0.684 & 0.643 & 0.794 & 0.791 & 0.770 & 0.728 & 0.726 & 0.708 \\
\hline 4 & 0.240 & 0.239 & 0.255 & 0.561 & 0.561 & 0.555 & 0.763 & 0.762 & 0.762 & 0.576 & 0.575 & 0.559 \\
\hline 5 & 0.522 & 0.518 & 0.451 & 0.828 & 0.823 & 0.805 & 0.670 & 0.663 & 0.623 & 0.221 & 0.215 & 0.182 \\
\hline 6 & 0.383 & 0.382 & 0.368 & 0.569 & 0.569 & 0.556 & 0.751 & 0.749 & 0.731 & 0.500 & 0.497 & 0.479 \\
\hline 7 & 0.309 & 0.309 & 0.287 & 0.774 & 0.774 & 0.758 & 0.690 & 0.690 & 0.669 & 0.231 & 0.229 & 0.201 \\
\hline 8 & 0.441 & 0.437 & 0.403 & 0.730 & 0.728 & 0.716 & 0.760 & 0.757 & 0.731 & 0.499 & 0.494 & 0.465 \\
\hline 9 & 0.318 & 0.318 & 0.312 & 0.547 & 0.547 & 0.541 & 0.669 & 0.669 & 0.652 & 0.342 & 0.342 & 0.328 \\
\hline 10 & 0.436 & 0.436 & 0.427 & 0.799 & 0.799 & 0.796 & 0.776 & 0.776 & 0.768 & 0.439 & 0.439 & 0.431 \\
\hline 11 & 0.148 & 0.148 & 0.145 & 0.333 & 0.333 & 0.329 & 0.690 & 0.687 & 0.654 & 0.626 & 0.624 & 0.585 \\
\hline 12 & 0.337 & 0.337 & 0.333 & 0.528 & 0.526 & 0.533 & 0.751 & 0.751 & 0.759 & 0.481 & 0.480 & 0.478 \\
\hline 13 & 0.174 & 0.174 & 0.154 & 0.665 & 0.665 & 0.641 & 0.955 & 0.955 & 0.952 & 0.684 & 0.683 & 0.671 \\
\hline 14 & 0.342 & 0.341 & 0.322 & 0.618 & 0.616 & 0.595 & 0.751 & 0.749 & 0.728 & 0.428 & 0.425 & 0.400 \\
\hline Mean & 0.363 & 0.362 & 0.340 & 0.656 & 0.654 & 0.640 & 0.753 & 0.751 & 0.733 & 0.466 & 0.464 & 0.443 \\
\hline SD & 0.119 & 0.118 & 0.105 & 0.139 & 0.138 & 0.134 & 0.076 & 0.077 & 0.086 & 0.160 & 0.161 & 0.163 \\
\hline
\end{tabular}

Table 6. Results of the precipitation detection capacity analysis (CSI and FBI).

\begin{tabular}{|c|c|c|c|c|c|c|c|c|c|c|c|c|}
\hline \multirow{7}{*}{ Station ID } & \multicolumn{12}{|c|}{ Indicator } \\
\hline & \multicolumn{6}{|c|}{ CSI } & \multicolumn{6}{|c|}{ FBI } \\
\hline & \multicolumn{6}{|c|}{ Temporal Aggregation Level } & \multicolumn{6}{|c|}{ Temporal Aggregation Level } \\
\hline & 30 & 30 & 30 & 24 & 24 & 24 & 30 & 30 & 30 & 24 & 24 & 24 \\
\hline & $(\min )$ & $(\min )$ & $(\min )$ & (h) & (h) & (h) & (min) & (min) & (min) & (h) & (h) & (h) \\
\hline & \multicolumn{3}{|c|}{ Threshold } & \multicolumn{3}{|c|}{ Threshold } & \multicolumn{3}{|c|}{ Threshold } & \multicolumn{3}{|c|}{ Threshold } \\
\hline & $>0$ & $\geq 0.1$ & $\geq 0.25$ & $>0$ & $\geq 0.1$ & $\geq 0.25$ & $>0$ & $\geq 0.1$ & $\geq 0.25$ & $>0$ & $\geq 0.1$ & $\geq 0.25$ \\
\hline 1 & 0.135 & 0.136 & 0.140 & 0.415 & 0.415 & 0.426 & 2.463 & 2.440 & 1.978 & 1.461 & 1.459 & 1.344 \\
\hline 2 & 0.246 & 0.246 & 0.256 & 0.635 & 0.636 & 0.642 & 1.633 & 1.633 & 1.353 & 1.096 & 1.094 & 1.038 \\
\hline 3 & 0.170 & 0.172 & 0.181 & 0.242 & 0.243 & 0.251 & 2.372 & 2.341 & 1.991 & 2.533 & 2.495 & 2.200 \\
\hline 4 & 0.136 & 0.135 & 0.140 & 0.318 & 0.319 & 0.325 & 1.012 & 1.005 & 1.071 & 1.322 & 1.320 & 1.259 \\
\hline 5 & 0.254 & 0.256 & 0.259 & 0.670 & 0.672 & 0.683 & 1.583 & 1.537 & 1.197 & 1.063 & 1.047 & 0.985 \\
\hline 6 & 0.178 & 0.179 & 0.184 & 0.363 & 0.364 & 0.368 & 1.535 & 1.522 & 1.368 & 1.137 & 1.131 & 1.067 \\
\hline 7 & 0.183 & 0.183 & 0.182 & 0.628 & 0.629 & 0.636 & 0.995 & 0.994 & 0.867 & 1.007 & 1.004 & 0.948 \\
\hline 8 & 0.184 & 0.185 & 0.192 & 0.423 & 0.426 & 0.442 & 1.838 & 1.798 & 1.499 & 1.456 & 1.439 & 1.339 \\
\hline 9 & 0.194 & 0.194 & 0.197 & 0.426 & 0.426 & 0.428 & 0.961 & 0.961 & 0.899 & 0.830 & 0.830 & 0.804 \\
\hline 10 & 0.174 & 0.174 & 0.177 & 0.491 & 0.492 & 0.497 & 1.944 & 1.943 & 1.845 & 1.425 & 1.424 & 1.398 \\
\hline 11 & 0.111 & 0.111 & 0.114 & 0.214 & 0.215 & 0.225 & 0.476 & 0.471 & 0.418 & 0.892 & 0.886 & 0.793 \\
\hline 12 & 0.167 & 0.167 & 0.162 & 0.354 & 0.354 & 0.358 & 1.356 & 1.354 & 1.381 & 1.017 & 1.012 & 1.020 \\
\hline 13 & 0.037 & 0.037 & 0.038 & 0.273 & 0.274 & 0.278 & 3.857 & 3.846 & 3.234 & 2.105 & 2.096 & 1.946 \\
\hline 14 & 0.169 & 0.169 & 0.173 & 0.423 & 0.423 & 0.426 & 1.374 & 1.360 & 1.184 & 1.080 & 1.071 & 0.992 \\
\hline Mean & 0.167 & 0.167 & 0.171 & 0.420 & 0.421 & 0.428 & 1.673 & 1.658 & 1.449 & 1.316 & 1.308 & 1.224 \\
\hline SD & 0.054 & 0.054 & 0.055 & 0.144 & 0.145 & 0.145 & 0.834 & 0.829 & 0.675 & 0.477 & 0.470 & 0.410 \\
\hline
\end{tabular}

Maximum Values; $\square \quad$ Minimum Values; $\square \quad$ Values close to 1 ; SD = Standard deviation. 
3.2. Quantification of the Precision or Discrepancy between the CMORPH Estimates and the Precipitation Data of the Rain Gauges

In this section, we present the results of the second evaluation approach. Table 7 concentrates the results of the precision quantification or discrepancy between the CMORPH estimates and the precipitation data of the rain gauges. The maximum values are highlighted with a blue border and the minimum values with a red border around the number. Additionally, of the differences between the precipitation estimated by the CMORPH algorithm and the precipitation observed by the rain gauge, the mean and maximum values of the positive differences were determined for each station, and the mean and minimum values of the negative differences were also determined. For the $30 \mathrm{~min}$ data, station 8 presented the minimum difference (underestimation) $-121.75 \mathrm{~mm}$ with a mean value with respect to the negative differences of $-0.033 \mathrm{~mm}$ and a standard deviation of $0.792 \mathrm{~mm}$ for a total of 185,234 analyzed data; station 10 presented the maximum difference (overestimation) of $85.25 \mathrm{~mm}$ with a mean value with respect to positive differences of $0.195 \mathrm{~mm}$ and a standard deviation of $1.457 \mathrm{~mm}$ for a total of 245,204 analyzed data. For the $24 \mathrm{~h}$ data, station 12 presented both the minimum difference (underestimation) $-360.33 \mathrm{~mm}$ with an average value with respect to the negative differences of $-0.817 \mathrm{~mm}$ and a standard deviation of $6.600 \mathrm{~mm}$, and the maximum difference (overestimation) $566.76 \mathrm{~mm}$ with a mean value with respect to the positive differences of $2.869 \mathrm{~mm}$ and a standard deviation of $15.893 \mathrm{~mm}$ for a total of 4169 analyzed data. The maximum and minimum annual values of the positive and negative differences, respectively, were also determined for each station, together with the empirical probability of each of these, which was calculated with the Weibull formula.

In Figures 6 and 7 we present a sample of the results of the maximum and minimum annual values of the positive and negative differences concerning the probability of exceedance. These results correspond to the stations with the highest and lowest values. These Figures show how often the maximum and minimum values were presented since these values alone seem alarming, but as can be seen, they do not appear frequently.

Table 7. Overall results of the precision quantification or discrepancy between the CMORPH estimates and the precipitation data of the rain gauges.

\begin{tabular}{|c|c|c|c|c|c|c|c|c|}
\hline \multirow{2}{*}{ Station ID } & \multicolumn{2}{|c|}{ MAE } & \multicolumn{2}{|c|}{ RMSE } & \multicolumn{2}{|c|}{ RB } & \multicolumn{2}{|c|}{$\mathrm{CC}$} \\
\hline & $30 \mathrm{~min}$ & $24 \mathrm{~h}$ & $30 \mathrm{~min}$ & $24 \mathrm{~h}$ & $30 \mathrm{~min}$ & $24 \mathrm{~h}$ & $30 \mathrm{~min}$ & $24 \mathrm{~h}$ \\
\hline 1 & 0.048 & 1.825 & 0.445 & 7.524 & 2.616 & 2.856 & 0.219 & 0.466 \\
\hline 2 & 0.121 & 4.065 & 0.748 & 11.173 & 0.921 & 0.951 & 0.250 & 0.529 \\
\hline 3 & 0.025 & 0.969 & 0.467 & 9.411 & 2.816 & 3.223 & 0.168 & 0.464 \\
\hline 4 & 0.091 & 3.021 & 0.750 & 10.866 & 0.721 & 0.746 & 0.197 & 0.546 \\
\hline 5 & 0.085 & 2.391 & 0.557 & 6.599 & 0.299 & 0.323 & 0.260 & 0.608 \\
\hline 6 & 0.087 & 3.070 & 0.890 & 13.854 & 1.279 & 1.386 & 0.237 & 0.563 \\
\hline 7 & 0.134 & 4.171 & 0.629 & 9.299 & 0.424 & 0.420 & 0.233 & 0.477 \\
\hline 8 & 0.084 & 2.735 & 0.970 & 11.284 & 0.448 & 0.458 & 0.166 & 0.532 \\
\hline 9 & 0.183 & 6.802 & 1.398 & 25.500 & 0.578 & 0.650 & 0.213 & 0.495 \\
\hline 10 & 0.219 & 9.213 & 1.545 & 26.448 & 3.854 & 3.983 & 0.218 & 0.495 \\
\hline 11 & 0.026 & 0.960 & 0.423 & 5.790 & 0.401 & 0.416 & 0.234 & 0.652 \\
\hline 12 & 0.097 & 3.684 & 1.077 & 17.460 & 1.154 & 1.222 & 0.139 & 0.367 \\
\hline 13 & 0.125 & 5.234 & 0.730 & 12.546 & 3.173 & 3.199 & 0.018 & 0.111 \\
\hline 14 & 0.059 & 2.121 & 0.557 & 7.718 & 0.893 & 0.903 & 0.193 & 0.471 \\
\hline
\end{tabular}




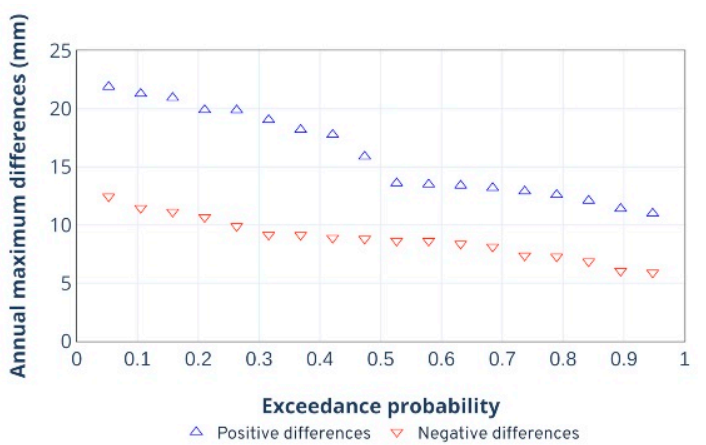

(a)

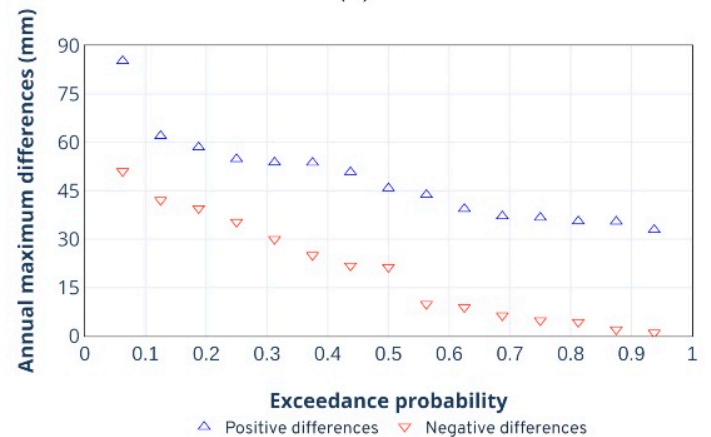

(c)

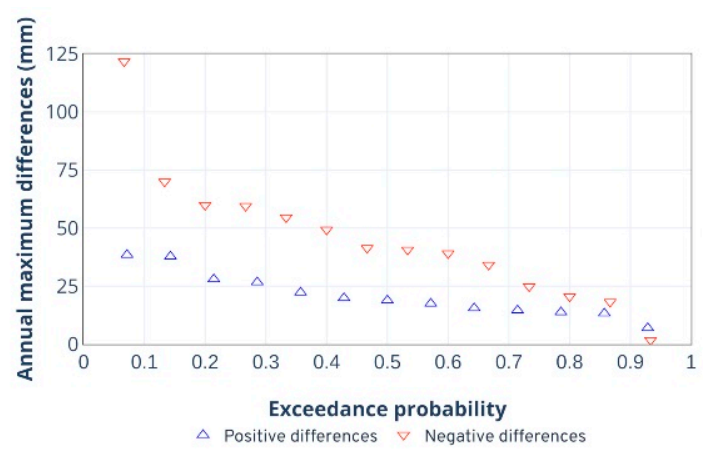

(b)

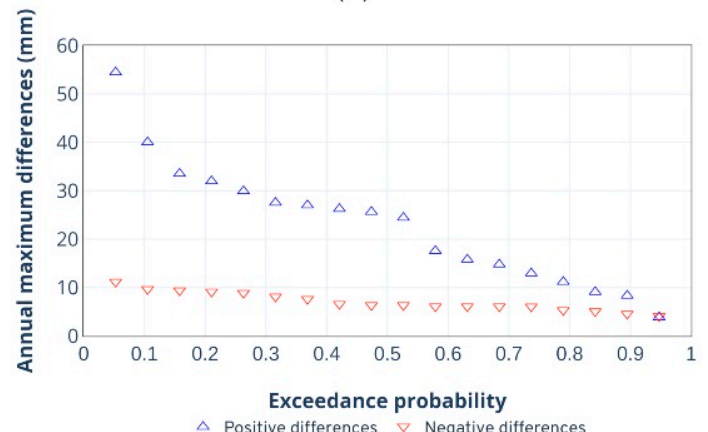

(d)

Figure 6. Results of the maximum annual differences between the precipitation estimated by the CMORPH algorithm and the precipitation observed in the station, for some of the analyzed stations. Accumulated precipitation in 30 min: (a) Station 7; (b) Station 8; (c) Station 10; (d) Station 11.

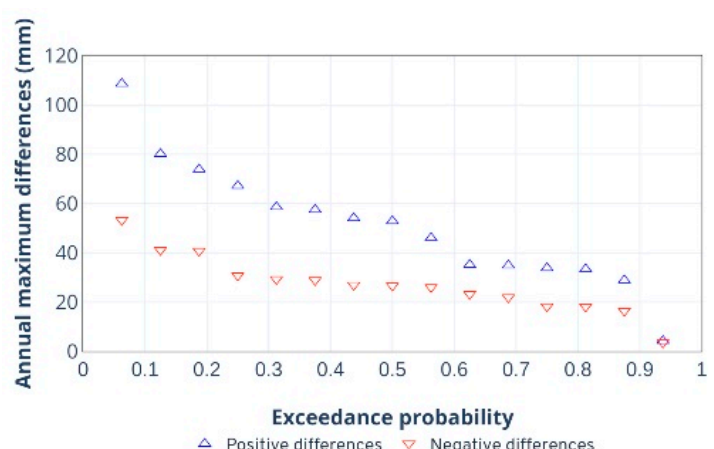

(a)

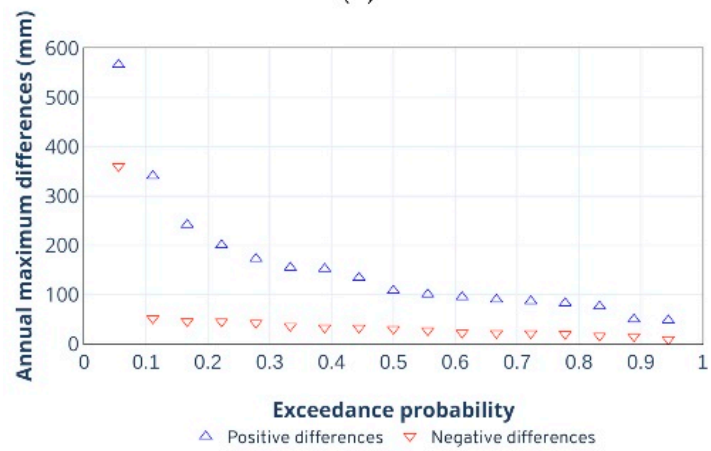

(c)

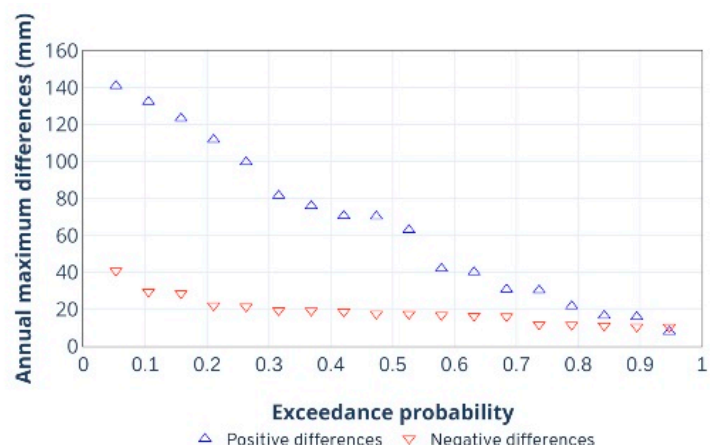

(b)

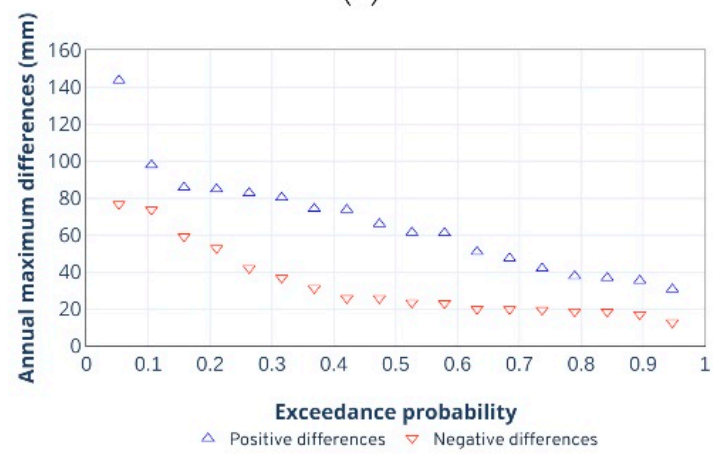

(d)

Figure 7. Results of the maximum annual differences between the precipitation estimated by the CMORPH algorithm and the precipitation observed in the station, for some of the analyzed stations. Accumulated precipitation in 24 h: (a) Station 5; (b) Station 11; (c) Station 12; (d) Station 14. 


\section{Discussion}

Due to the small changes in value at the thresholds used, very slight trends are observed in the indicators; however, the trends of POD and CSI agree with those found by Alijanian et al. and Jiang et al. [1,6], where an increase in the threshold value results in a decrease in the detection capacity. The CMORPH-CRT product presented a better performance in the detection capacity at the level of temporal aggregation of a day (Figure 8), which is consistent with the results presented in the work of Jiang et al. that show a better performance of the SBP for the monthly scale than for the daily scale [6]. For the precipitation data accumulated in $30 \mathrm{~min}$, POD values $>0.4$ were obtained in 5 of the 14 stations and in no case exceeded 0.5 , so the detection capacity for this level of aggregation is relatively poor. The detection capacity for the accumulated precipitation data in $24 \mathrm{~h}$ is much better since in 8 of the 14 stations POD values $>0.64$ were obtained and only one station presented a POD value $<0.5$. The highest values of POD were obtained in stations located in regions with a mild temperate climate with dry winters and warm summers $(\mathrm{Cwb})$. On the other hand, it was found that CMORPH-CRT product overestimates the number of precipitation events in most cases, since we obtained FBI values greater than 1 , in 11 of the 14 stations analyzed. These results are consistent with what was found by Kumar et al. that presented FBI values greater than 1, in 5 of the 6 stations analyzed [7].

With respect to the quantification of the precision or discrepancy between the CMORPH estimates and the precipitation data of the rain gauges, CC values were found in the ranges of 0.018 to 0.260 for the precipitation data accumulated in $30 \mathrm{~min}$, which indicates a weak correlation. For the precipitation data accumulated in $24 \mathrm{~h}, \mathrm{CC}$ values were found in the ranges from 0.111 to 0.625 ; of the 14 stations, 2 had a weak correlation with $\mathrm{CC}<0.4,10$ showed a moderate correlation with $0.4<\mathrm{CC}<0.6$ and 2 had a strong correlation with CC $>0.6$ (Figure 9). These results are consistent with the $\mathrm{CC}$ values reported by Kumar et al. and Haile et al. [7,8].

Regarding the RB indicator, it was found that in all stations the CMORPH-CRT product overestimates the precipitation $(\mathrm{RB}>0)$, unlike Jiang et al. and Kumar et al. who reported that in all the analysis sites the CMORPH algorithm underestimates precipitation $[6,7]$. These results were contrasted with the types of climate to determine if there is any relationship. Of the 8 climates analyzed, in each type of climate, there are 2 stations except for the tropical monsoon (Am) and tundra (ET) climates in which there is only one station. For stations located in sites with the same climate, CMORPH-CRT product showed consistency when having the same range of values of RB; for example, stations 1 and 3 that are located in sites with hot desert (arid) climate (BWh), both resulted with a RB $>1$, and stations 2 and 5 that are located in sites with mild temperate climate with dry winters and warm summers (Cwb), both resulted with a $0<\mathrm{RB}<1$.

\section{Conclusions}

The performance of the SBP CMORPH-CRT product was evaluated against precipitation data from 14 automatic meteorological stations in Mexico, for two levels of temporal aggregation: $30 \mathrm{~min}$ and daily. The following conclusions can be drawn from the results obtained in the study:

1. The CMORPH-CRT product has a better performance for the daily aggregation level than for the $30 \mathrm{~min}$ level, both in the detection capacity and in the accuracy of the precipitation estimation.

2. For the two levels of temporal aggregation, the CMORPH-CRT product overestimates the number of precipitation events, that is, detects more events than actually occurs.

3. With respect to the accuracy, for the two levels of temporal aggregation, the CMORPH-CRT product tends to overestimate the amount of precipitation.

4. The results of the analysis of maximum annual differences clearly show the risk of introducing major errors when using the CMORPH-CRT product in hydrological analyzes, research should be conducted focused on identifying the causes of the differences. One of the causes could be the difference in the spatial sampling of the rain gauge and the SBP product since the first provides point measurements and the last delivers spatial averages over the area of a grid cell. The rain 
gauge may not be detecting convective precipitation events located over the area of the grid cell of the SBP product [16].

We consider that a broader sample of stations is required to consolidate these conclusions, so in future works, we will seek to incorporate a greater number of stations to the analysis. It is also intended to extend the study to thresholds that allow categorizing precipitation into classes according to their intensity and perform a detailed analysis for each season of the year, which includes relationships with the height and physiography of the sites, in order to obtain a better understanding of the advantages or risks of using the SBP CMORPH-CRT product in hydrological analyzes.
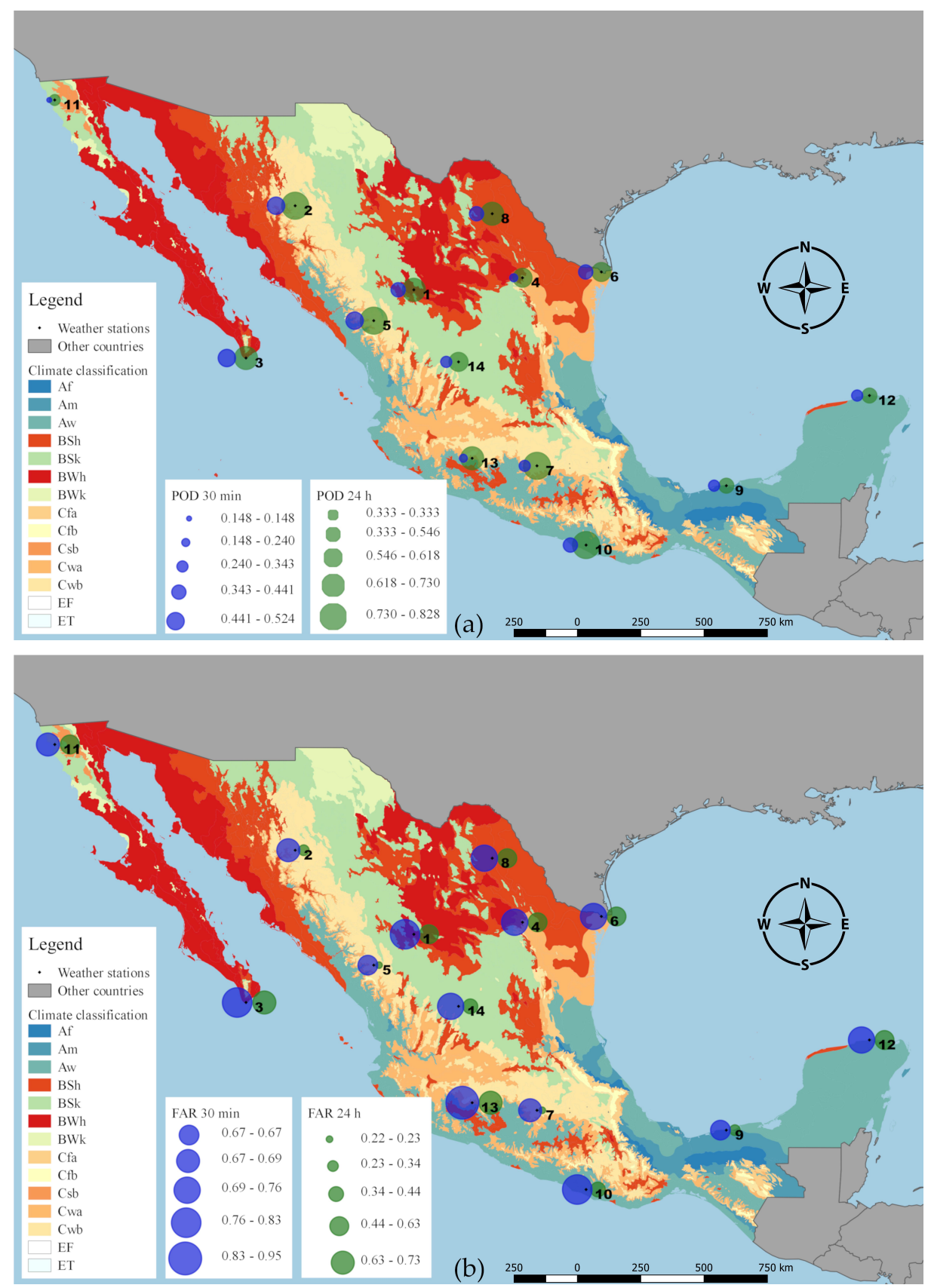

Figure 8. Spatial distribution of (a) POD and (b) FAR of the SBP CMORPH-CTR product on the study sites, for the two analyzed levels of temporal aggregation. 

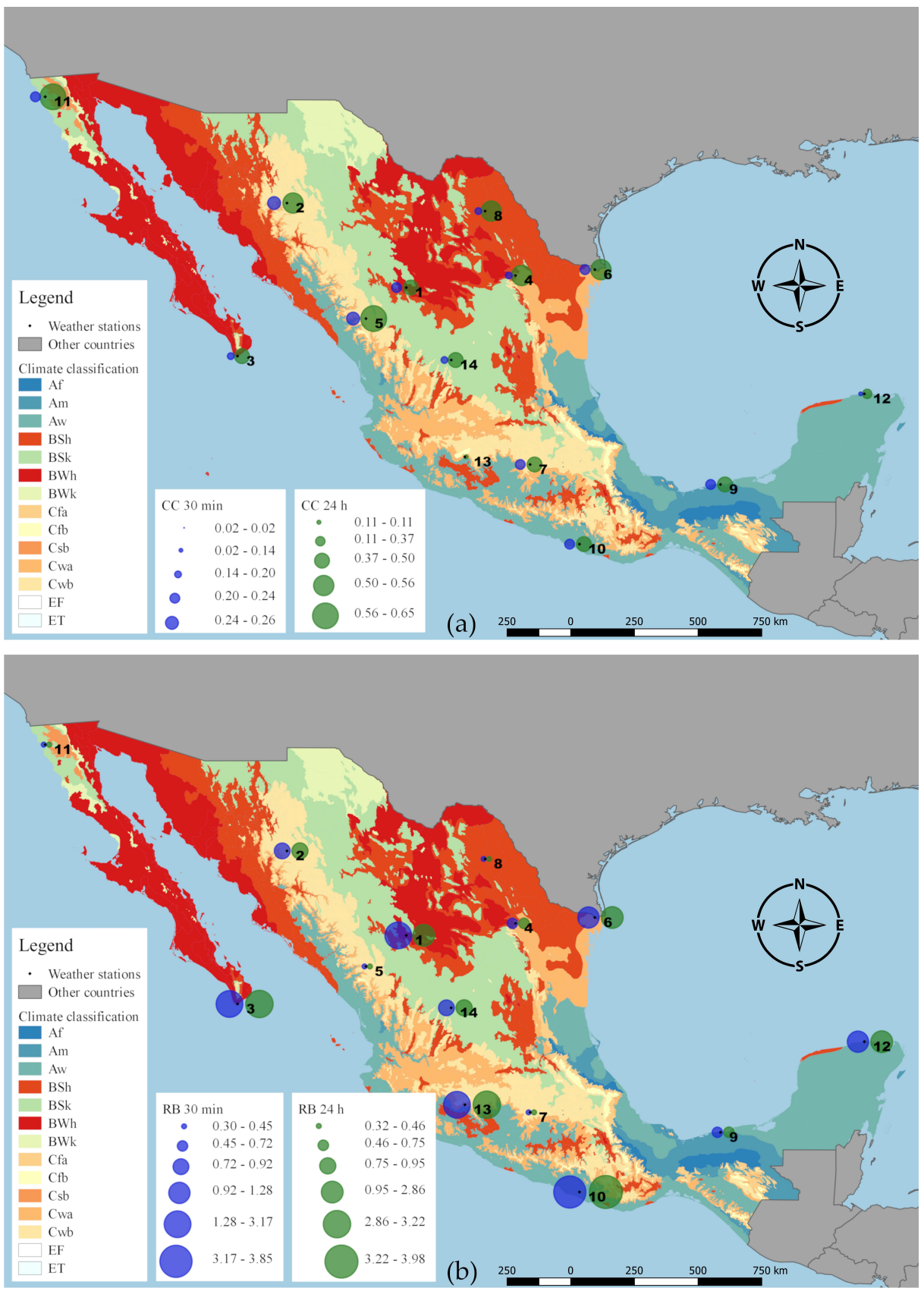

Figure 9. Spatial distribution of (a) CC and (b) RB obtained from the analysis between the precipitation data observed by the weather stations and the CMORPH estimates, for the two levels of temporal aggregation analyzed.

Author Contributions: Conceptualization, J.L.B.-F. and R.O.-G.; methodology, J.L.B.-F. and R.O.-G.; software, J.L.B.-F.; formal analysis, J.L.B.-F. and A.L.F.-F.; investigation, J.L.B.-F. and V.H.G.-C.; data curation, J.L.B.-F. writing-original draft preparation, J.L.B.-F. and A.L.F.-F.; writing-review and editing, R.O.-G., V.H.G.-C., D.B.-F. and L.G.L.-M.; visualization, J.L.B.-F.; supervision, R.O.-G., A.L.F.-F., V.H.G.-C., D.B.-F. and L.G.L.-M.; project administration, R.O.-G., A.L.F.-F. and D.B.-F.

Funding: This research received no external funding.

Acknowledgments: The authors are thankful to General Coordination of the National Meteorological Service for providing precipitation data.

Conflicts of Interest: The authors declare no conflict of interest. 


\section{Appendix A}

As mentioned in Section 2.1.2, the SBP CMORPH-CRT product is available on FTP site of the CPC in files with the extension ".tar" for each month. The name of the ".tar" file describes the information about the data it contains, for example, in "CMORPH_V1.0_ADJ_8km-30min_199801.tar", "CMORPH" indicates the algorithm used to generate the satellite precipitation product, "V1. 0" the product version, "ADJ" which is about the estimates with correction of bias, " $8 \mathrm{~km}-30 \mathrm{~min}$ " the spatial and temporal resolution, finally, "199801" indicates the year and month. The ".tar" files contain a folder with a total of "nd $\times 24$ " files with extension ".bz2" compressed with bzip2, being nd the number of days of the month. The name of the ".bz2" file describes information about the data it contains, using the same structure as the name of the ".tar" files, except for the part related to the date that, in addition to the year and month, includes day and UTC time. When you unzip the file ".bz2" you get a binary file with a size of $65,274,016$ bytes that contains numeric information stored in 32 bits floating-point format. This numerical information consists of two sets of estimates of accumulated precipitation in $30 \mathrm{~min}$, covering the entire planet between latitudes $60^{\circ} \mathrm{S}$ to $60^{\circ} \mathrm{N}$, with a resolution of $0.072771377^{\circ}$ for latitude and $0.072756669^{\circ}$ for longitude. The first set corresponds to the estimate of the accumulated precipitation between the interval of 30 to $60 \mathrm{~min}$ of the hour before that described in the file name and the second set corresponds to the accumulated one between the interval of 00 to $30 \mathrm{~min}$ of the hour described in the file name. Depending on the latitude and longitude resolutions, each set corresponds to an array of 4948 rows per 1649 columns, the rows correspond to the longitude and the columns to the latitude, so the information must be transposed. In addition, the information is arranged from south to north, so the order of the rows of the transposed array must be reversed. Once transposed and reversed, the center of the cell in the upper right corner of the array corresponds to the precipitation estimate for the site with latitude $59.963614^{\circ} \mathrm{N}$ and longitude $0.036378335^{\circ} \mathrm{E}$ on the date and time specified in the file name.

\section{References}

1. Alijanian, M.; Rakhshandehroo, G.R.; Mishra, A.K.; Dehghani, M. Evaluation of satellite rainfall climatology using CMORPH, PERSIANN-CDR, PERSIANN, TRMM, MSWEP over Iran. Int. J. Climatol. 2017, 37, 4896-4914. [CrossRef]

2. Sorooshian, S.; Hsu, K.L.; Gao, X.; Gupta, H.V.; Imam, B.; Braithwaite, D. Evaluation of PERSIANN system satellite-based estimates of tropical rainfall. Bull. Am. Meteorol. Soc. 2000, 81, 2035-2046. [CrossRef]

3. Joyce, R.J.; Janowiak, J.E.; Arkin, P.A.; Xie, P. CMORPH: A method that produces global precipitation estimates from passive microwave and infrared data at high spatial and temporal resolution. J. Hydrometeorol. 2004, 5, 487-503. [CrossRef]

4. Huffman, G.J.; Adler, R.F.; Bolvin, D.T.; Gu, G.; Nelkin, E.J.; Bowman, K.P.; Hong, Y.; Stocker, E.F.; Wolff, D.B. The TRMM Multisatellite Precipitation Analysis (TMPA): Quasi-global, multiyear, combined-sensor precipitation estimates at fine scales. J. Hydrometeorol. 2007, 8, 38-55. [CrossRef]

5. AghaKouchak, A.; Behrangi, A.; Sorooshian, S.; Hsu, K.; Amitai, E. Evaluation of satellite-retrieved extreme precipitation rates across the central United States. J. Geophys. Res. Atmos. 2011, 116, 1-11. [CrossRef]

6. Jiang, Q.; Li, W.; Wen, J.; Qiu, C.; Sun, W.; Fang, Q.; Xu, M.; Tan, J. Accuracy evaluation of two high-resolution satellite-based rainfall products: TRMM 3B42V7 and CMORPH in Shanghai. Water 2018, 10, 40. [CrossRef]

7. Kumar, B.; Patra, K.C.; Lakshmi, V. Daily rainfall statistics of TRMM and CMORPH: A case for trans-boundary Gandak river basin. J. Earth Syst. Sci. 2016, 125, 919-934. [CrossRef]

8. Haile, A.T.; Habib, E.; Rientjes, T. Evaluation of the climate prediction center (CPC) morphing technique (CMORPH) rainfall product on hourly time scales over the source of the Blue Nile River. Hydrol. Process. 2013, 27, 1829-1839. [CrossRef]

9. Nastos, P.T.; Kapsomenakis, J.; Philandras, K.M. Evaluation of the TRMM 3B43 gridded precipitation estimates over Greece. Atmos. Res. 2016, 169, 497-514. [CrossRef]

10. Wang, J.; Wolff, D.B. Evaluation of TRMM rain estimates using ground measurements over central Florida. J. Appl. Meteorol. Climatol. 2012, 51, 926-940. [CrossRef] 
11. Quirino, D.T.; Casaroli, D.; Jucá Oliveira, R.A.; Mesquita, M.; Pego Evangelista, A.W.; Alves Júnior, J. Evaluation of TRMM satellite rainfall estimates (algorithms 3B42 V7 \& RT) over the Santo Antônio county (Goiás, Brazil). Rev. Fac. Nac. Agron. 2017, 70, 8251-8261.

12. Ávila-Carrasco, J.R.; Júnez-Ferreira, H.E.; Gowda, P.H.; Steiner, J.L.; Moriasi, D.N.; Starks, P.J.; Gonzalez, J.; Villalobos, A.A.; Bautista-Capetillo, C. Evaluation of satellite-derived rainfall data for multiple physio-climatic regions in the Santiago River Basin, Mexico. J. Am. Water Resour. Assoc. 2018, 54, 1068-1086. [CrossRef]

13. Xie, P.; Joyce, R.; Wu, S.; Yoo, S.H.; Yarosh, Y.; Sun, F.; Lin, R. Reprocessed, bias-corrected CMORPH global high-resolution precipitation estimates from 1998. J. Hydrometeorol. 2017, 18, 1617-1641. [CrossRef]

14. Zhang, C.; Chen, X.; Shao, H.; Chen, S.; Liu, T.; Chen, C.; Ding, Q.; Du, H. Evaluation and intercomparison of high-resolution satellite precipitation estimates-GPM, TRMM, and CMORPH in the Tianshan Mountain Area. Remote Sens. 2018, 10, 1543. [CrossRef]

15. Jiménez-Jiménez, S.I.; Ojeda-Bustamante, W.; Ontiveros-Capurata, R.E.; Flores-Velázquez, J.; de Marcial-Pablo, M.J.; Robles-Rubio, B.D. Quantification of the error of digital terrain models derived from images acquired with UAV. Ing. Agrícola Biosist. 2017, 9, 85-100. [CrossRef]

16. Cánovas-García, F.; García-Galiano, S.; Alonso-Sarría, F. Assessment of satellite and radar quantitative precipitation estimates for real time monitoring of meteorological extremes over the southeast of the Iberian Peninsula. Remote Sens. 2018, 10, 1023. [CrossRef]

(C) 2019 by the authors. Licensee MDPI, Basel, Switzerland. This article is an open access article distributed under the terms and conditions of the Creative Commons Attribution (CC BY) license (http://creativecommons.org/licenses/by/4.0/). 